\title{
Relationships between Particle Precipitation and Auroral Forms
}

\author{
J.L. BURCH ${ }^{*, * *}$ and J.D. WINNINGHAM ${ }^{* * *}$ \\ *Southwest Research Institute, San Antonio, Texas 78284, U.S.A. \\ **University of Texas at San Antonio, San Antonio, Texas 78285, U.S.A. \\ ***University of Texas at Dallas, Richardson, Texas 75080, U.S.A.
}

(Received February 7, 1978)

\begin{abstract}
The present state of knowledge on the relationships between high-latitude particle precipitation and the aurora is reviewed. Attention is focused on the largescale relationships between auroral forms and magnetospheric particle populations, on the relationships between satellite and sounding-rocket measurements, and on the interaction of auroral electrons with the atmosphere. While significant progress is being made in relating the large-scale features of the aurora to magnetospheric plasma domains, and in understanding the way in which auroral electrons deposit their energy in the atmosphere, only slight progress has been made in relating satellite data to the small-scale phenomena associated with auroral arcs.
\end{abstract}

\section{Introduction}

The purpose of this paper is to review the present state of knowledge on the relationship between high-latitude particle precipitation and the aurora. Due to length limitations the discussion covers only electron observations, and is somewhat restricted in scope, focusing chiefly on very recent measurements. The paper is divided into three main topics: (1) the large-scale relationships between auroral forms and the particle populations of the magnetosphere as determined from satellite measurements; (2) the relationship between satellite and sounding-rocket observations, particularly field-aligned pitch-angle distributions and upward field-aligned currents measured in the vicinity of auroral forms; and (3) recent results on the interaction of auroral electrons with the atmosphere.

\section{Satellite Observations of Particle Precipitation and the Aurora}

\subsection{Nightside observations}

The initial results of Ackerson and Frank (1972) and Winningham and Heikkila (1973), using data from ISIS 1 and 2 Injun 5, combined with all-sky camera and aircraft optical observations, have indicated a close relationship between inverted-' $V$ ' type electron precipitation and discrete auroral forms in the eveningside auroral oval, the afternoon-quadrant cleft and the polar cap. The availability of global auroral images from ISIS and DMSP has subsequently allowed significant extensions of this work to be made. 


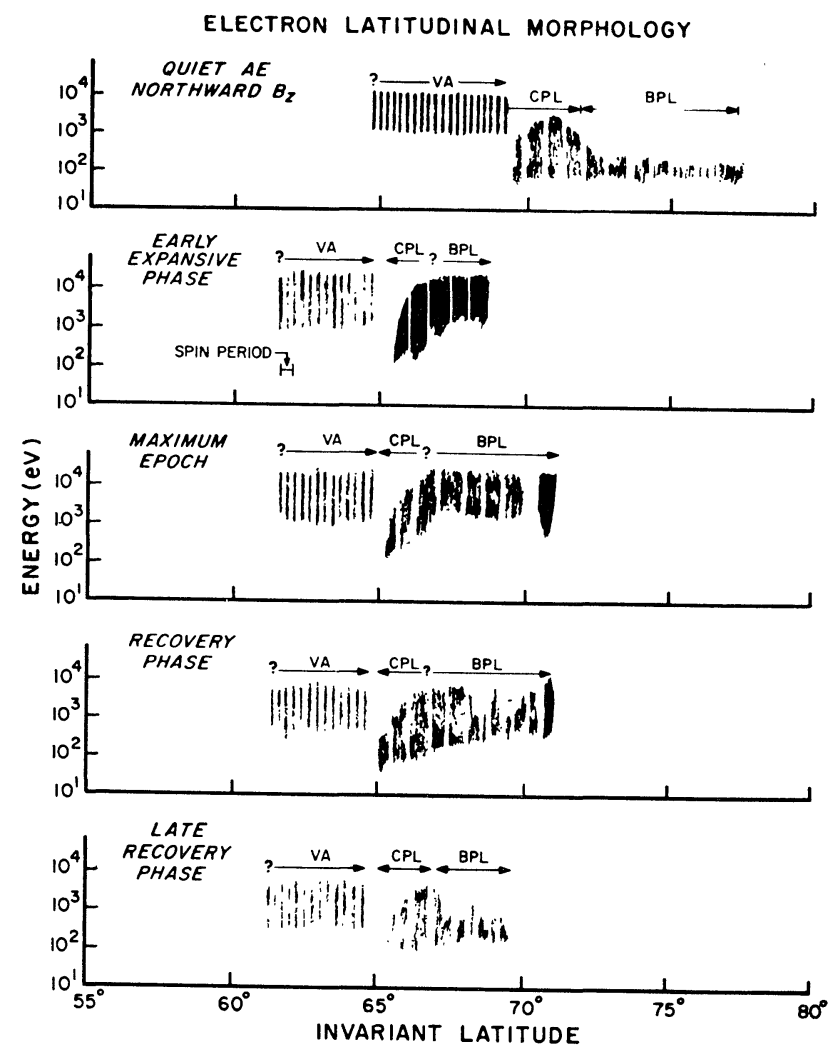

Fig. 1. Schematic representation of the latitudinal morphology of electron precipitation in the 21-03 MLT sector during substorms as deduced by WinNINGHAM et al. (1975).

The nightside patterns of electron precipitation and their evolution during substorms has been described extensively by HofFMan and Burch (1973) and WINNINGHAM et al. (1975). Figure 1 shows schematic ISIS spectrograms (not real data) of nightside electron precipitation as presented in the Winningham et al. paper. The patterns of precipitating electrons are generally classifiable into diffuse and discrete zones attributed by Winningham et al. to sources in the central plasma sheet (CPS) and boundary plasma layer (BPL) respectively. As seen in Fig. 1, the occurrence of substorms is signaled by energization of the BPL electrons along with a general spreading in latitude of the entire precipitation zone and a distinct separation between the CPS and BPL.

The recent work of LUI et al. (1977) has established the relationship between these precipitation zones and auroral forms derived from ISIS global images. Figures 2 and 3 (taken from the Lui et al. paper) show electron data and auroral intensity profiles for both a substorm period (Fig. 2) and a quiet period (Fig. 3). In the Fig. 2 example, the auroral intensity profile indicates a discrete form located along the satellite path between 70.5 and $72.5^{\circ}$ invariant latitude. This form and the diffuse 


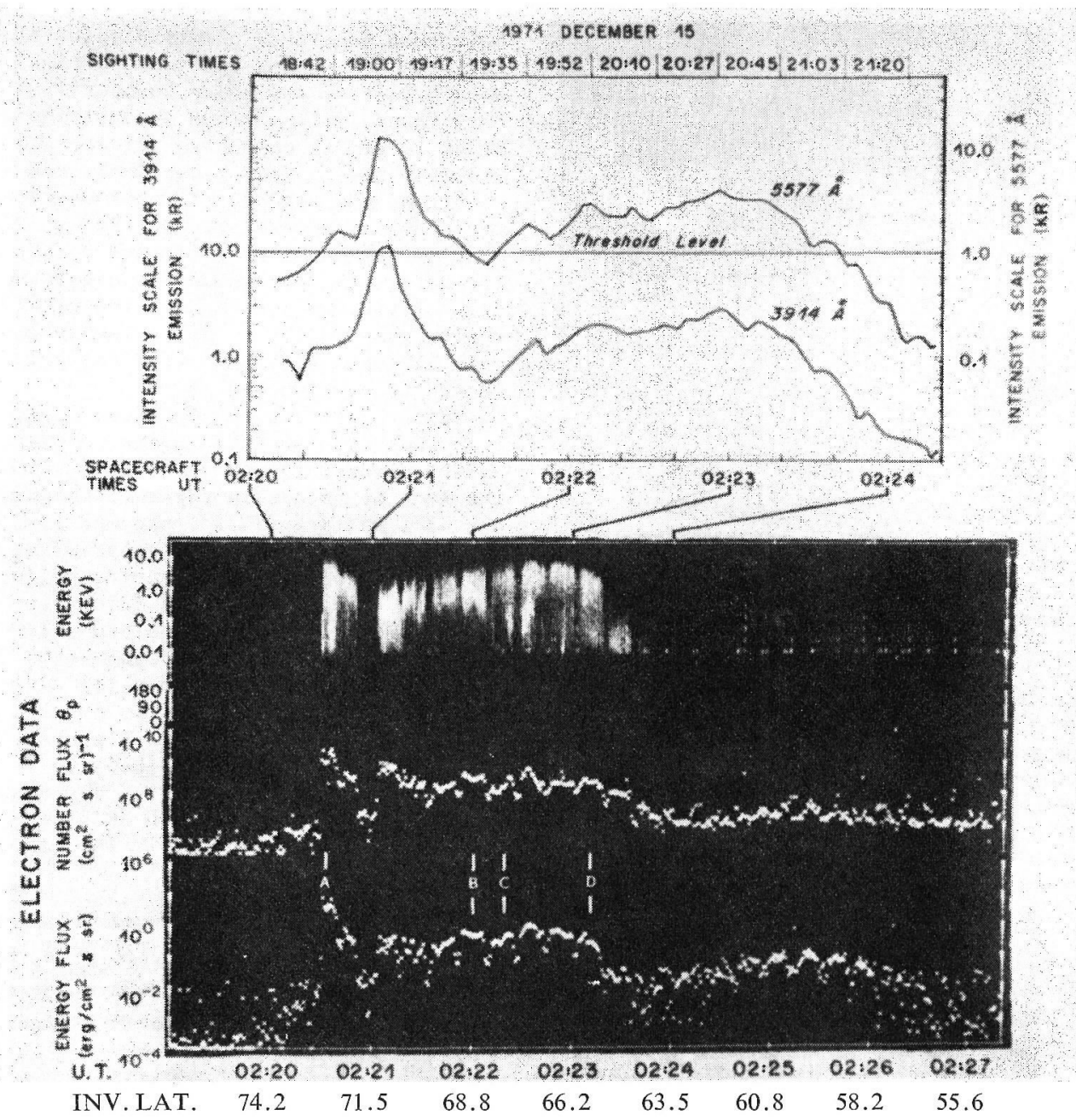

Fig. 2. Auroral intensity profiles along the magnetic projection of the ISIS 2 satellite orbit, and electron and proton data on December 15, 1971. (From Lur et al., 1977)

aurora (located between 64 and $70^{\circ}$ ) were separated by a region of weak emission. The electron data in Fig. 2 show a narrow region of structured and intense precipitation (the BPL) near $\lambda=72.5^{\circ}$, corresponding well with the discrete auroral emissions. As is the case for the auroral emissions, a region of very weak precipitation exists between the BPL and the CPS. The broad and uniform region of electron fluxes in the CPS are consistent with spatial coincidence with the diffuse auroral emissions.

This same correspondence between discrete auroral forms and the BPL and between diffuse auroral emissions and the CPS is main tained in the quiet cases examined by Lui et al. in which the BPL appeared to be attached to the poleward part of the CPS, as shown in Fig. 3. 


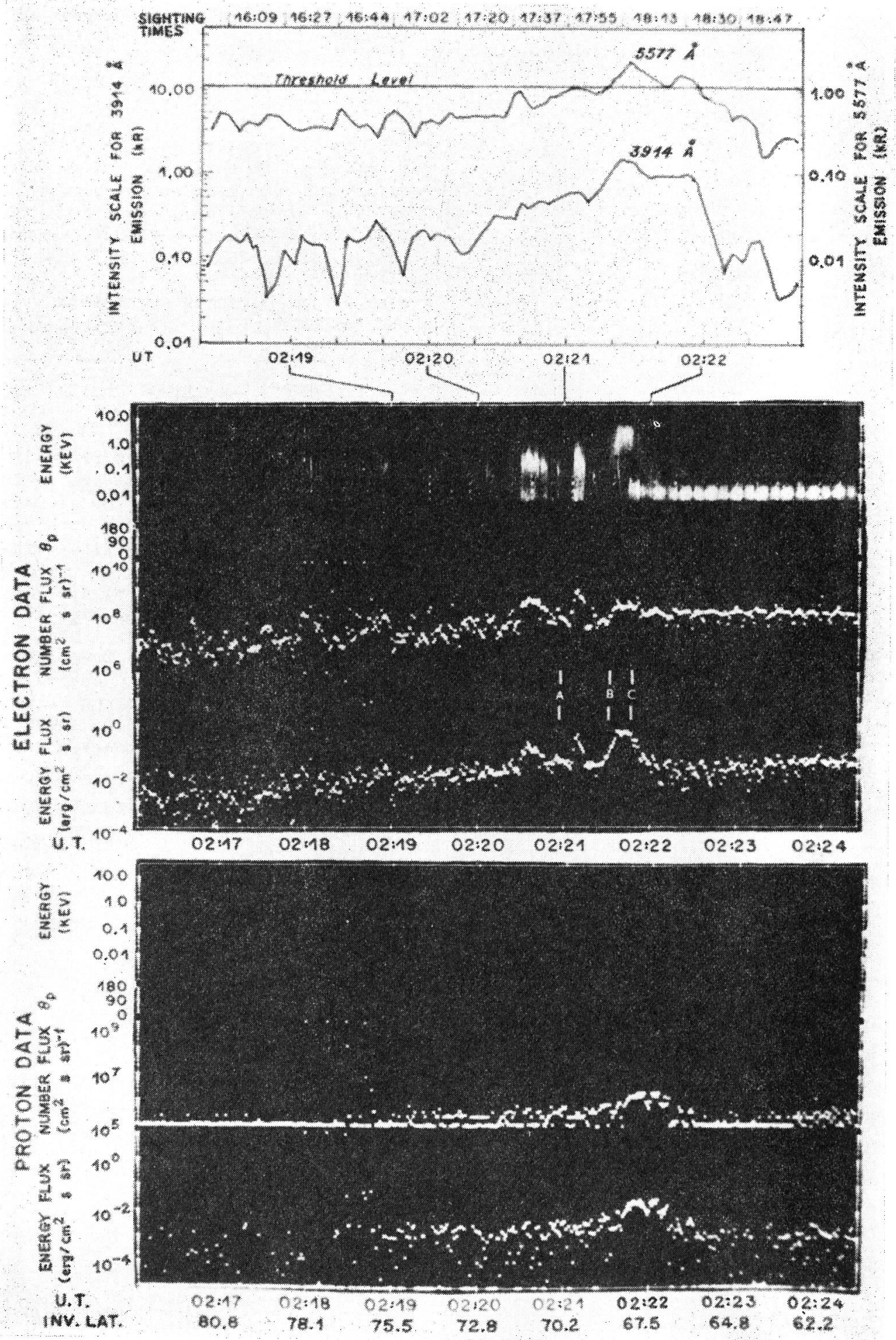

Fig. 3. Same as Fig. 2, except for December 21, 1971. 
As noted by Lur et al. (1977) and earlier by BURCH et al. (1976) and others, the distribution functions of electrons precipitating into the diffuse aurora region are generally Maxwellian in character, while those observed within the structured precipitation region are well-described by Maxwellian distributions that have been accelerated by a field-aligned electrostatic potential drop.

\subsection{Dayside observations}

Figure 4 is a DMSP image of dayside aurora taken from SNYDER and AKASOFU (1976). This picture shows a newly-observed feature-the V-shaped auroras fanning out from a central region near noon. A recent paper by ReIfF et al. (1977) suggests that the dark region corresponds to the dayside convection 'throat' described by

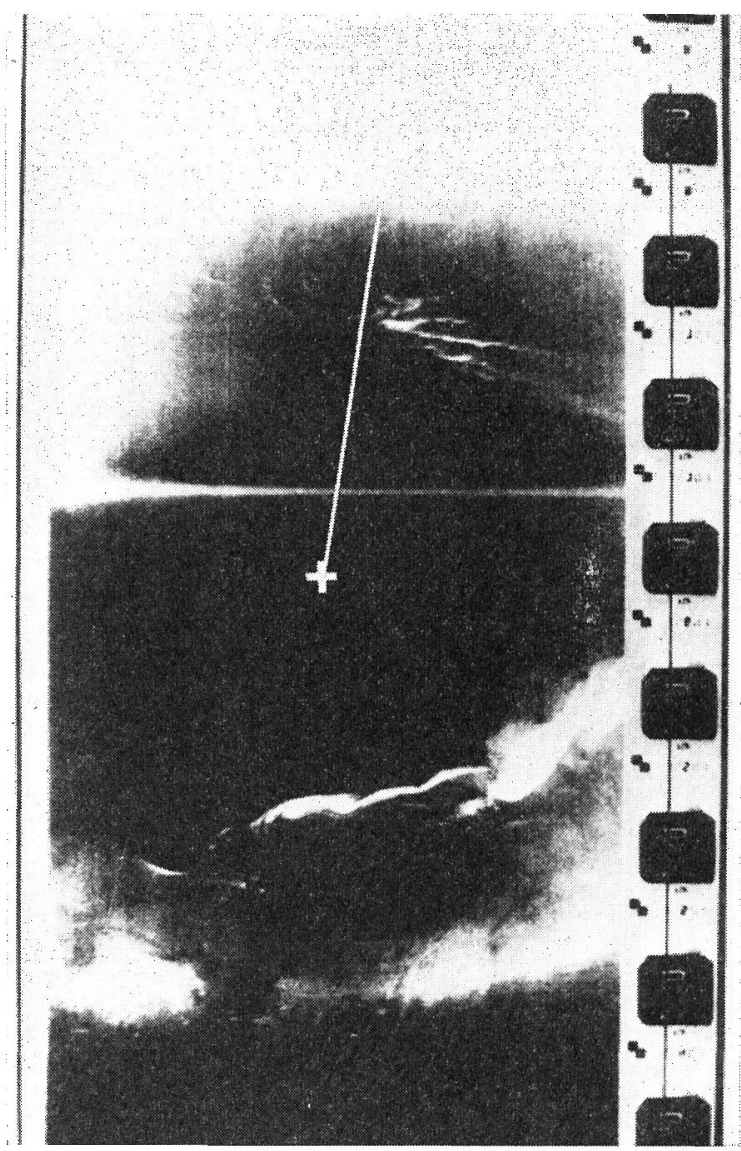

Fig. 4. An example of a DMSP photograph which was taken approximately along the noon-midnight meridian. The location of the invariant pole is shown by a cross, together with the isochronal line for magnetic noon at $1332 \mathrm{UT}$. The location of the south pole is shown by a dot; satellite DMSP 8531; orbit 5960; time, 1332 UT; date, May 10, 1975. (From SNYder and Akasofu, 1976) 
HeElis et al. (1976), while the auroral forms are associated with the convection shear reversals that occur at local times remote from the throat. This suggestion is based on the expected relationship between the dayside aurora and intense particle beams associated with the field-aligned currents required to support the convection shear reversals. Although the afternoon-quadrant auroral forms are probably associated with the inverted-' $V$ ' electron precipitation that is often observed there (MCDiarmid and Burrows, 1975; Burch et al., 1976; Winningham et al., 1977) it

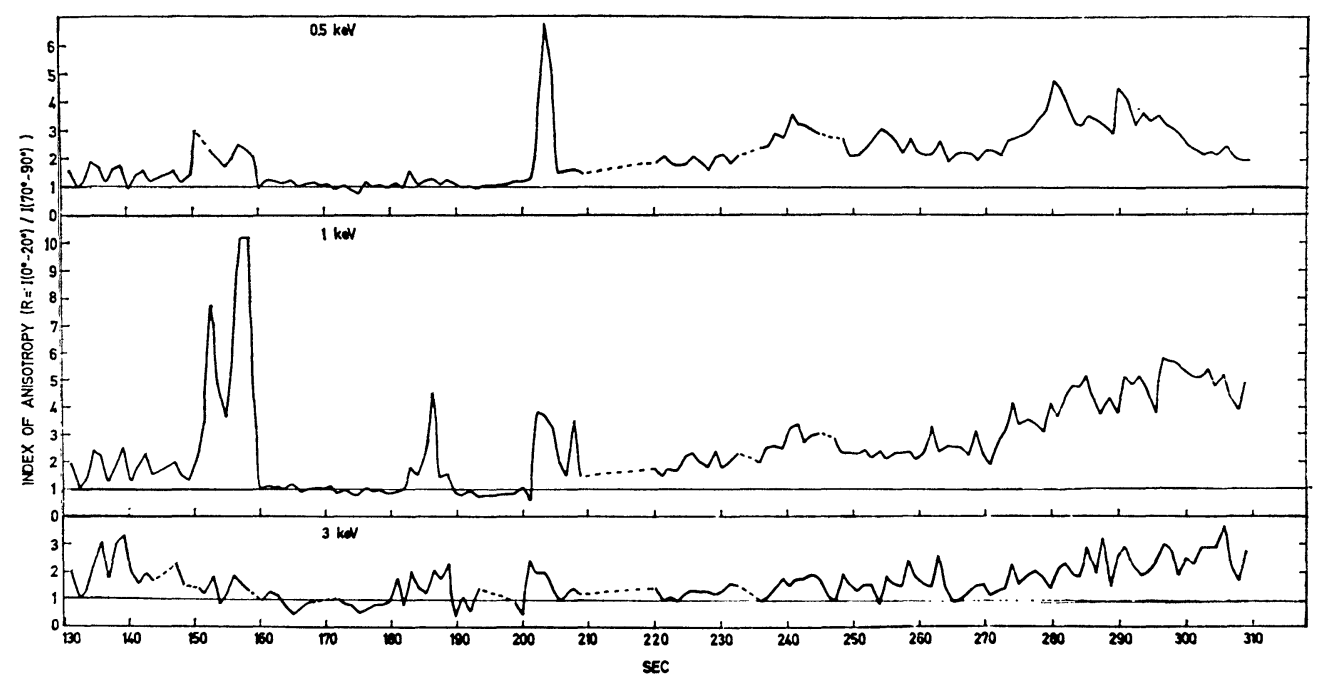

Fig. 5. Ratio between electron fluxes observed along and normal to the geomagnetic field lines. Auroral arcs were observed between 160 and $180 \mathrm{sec}$ and between 190 and $200 \mathrm{sec}$. (Taken from Maehlum and Mostue, 1973)



Fig. 6. Field-aligned current pattern as obtained by examining the divergence of the horizontal current system. (From Evans et al., 1977) 
is not clear what particle population produces the morning-quadrant auroras, since very little electron energization is observed in that sector of the cleft.

\section{Satellite versus Rocket Measurements}

A long-standing unanswered question in the field of auroral physics concerns relationship between the large-scale (100 to $300 \mathrm{~km}$ north-south) electron inverted-' $V$ ' structures and the much narrower $(.1$ to $10 \mathrm{~km})$ auroral arcs. The lack of structure



Fig. 7. Net current out of the ionosphere carried by the energetic electrons measured by the particle detectors on board the sounding rocket Polar 3, as reported by Evans et al. (1977).

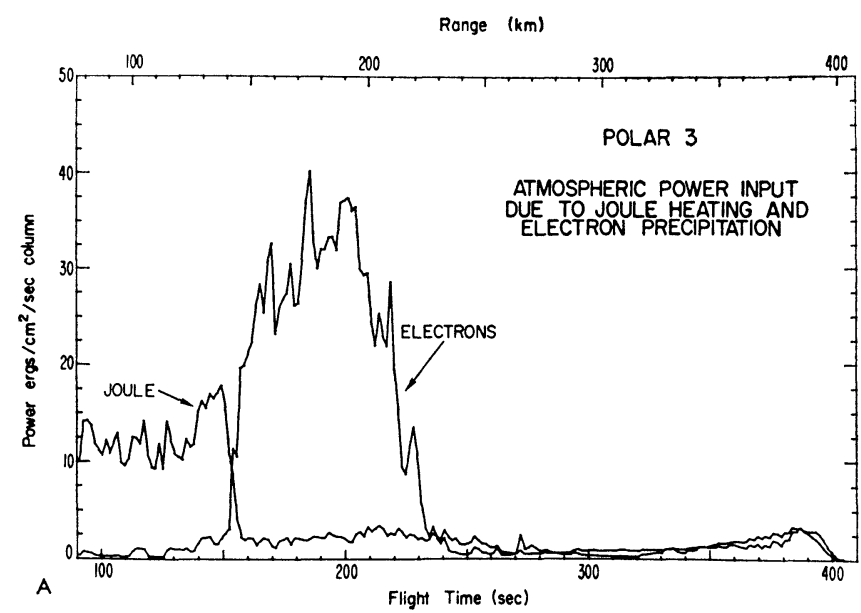

Fig. 8. Energy dissipated into the auroral atmosphere through Joule heating and by precipitating auroral electrons. That contribution provided by the particles defines the visual auroral arc. (From Evans et al., 1977) 
evident in many satellite measurements of inverted-' $\mathrm{V}$ ' electron beams results almost surely from the sparsity of measurements near zero pitch angle. An example of the structure observed near zero pitch angle has been presented by LIN and HofFMAN (1977). Their Atmosphere Explorer data exhibit a high degree of spatial structure at very small pitch angles and only at energies near and just below the spectral peak as this peak moves to higher and then to lower energies during the satellite's traversal of the inverted 'V.' One might suppose, then, that narrow field-aligned beams embedded in an inverted-' $V$ ' are responsible for the narrow regions of enhanced light output.

Rocket measurements of particle fluxes in the vicinity of auroral arcs have, however, indicated that this simple explanation is not valid. For example, Fig. 5 displays the rocket data of Maehlum and Mostue (1975), showing field-aligned beams at the edges of auroral arcs. Data which lend indirect support to this idea that field-aligned electron beams occur adjacent to, but not over, auroral arcs have been presented by Evans et al. (1977), and reproduced in Figs. 6 and 7 . Figure 7 displays the current carried by the measured electrons, while Fig. 6 displays the total field-aligned current deduced from gradients in the horizontal currents as derived from magnetometer data. Although the field-aligned current over the arc is roughly equal to that carried by the precipitating electrons, the strongest current appears in a narrow region just equatorward of the arc.

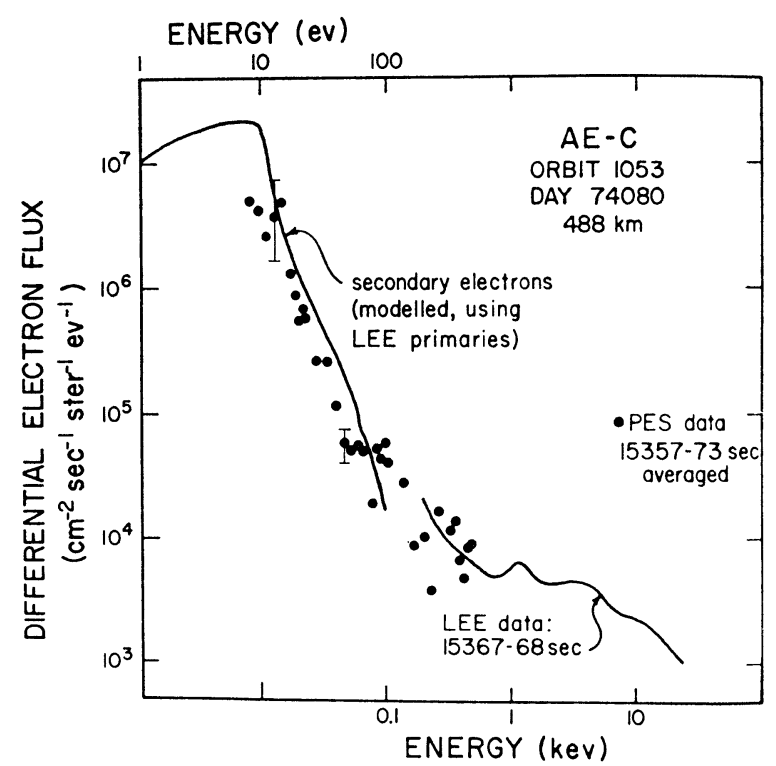

Fig. 9. Electron fluxes during the rocket-satellite coordination experiment of ReEs et al. (1977). The LEE (Low Energy Electron Experiment) measurements represent a 1-s spectral scan, while the PES (Photoelectron Spectrometer) data are averaged over a 15-s interval. The theoretical secondary electron spectrum is arbitrarily terminated at $100 \mathrm{eV}$. 


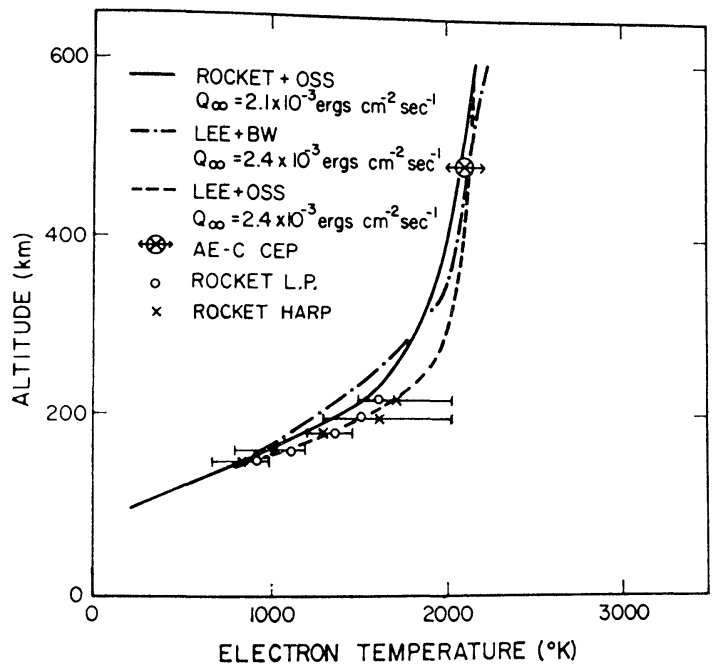

Fig. 10. Temperature measurements obtained with the rocket-borne Langmuir probe (LP), the hyperbolic electrostatic analyzer (HARP), and the satellite-borne cylindrical electrostatic probe (CEP) in the experiment of ReEs et al. (1977). The solid curves are altitude profiles of electron temperature deduced from model computations by using various input parameters indicated in the figure.

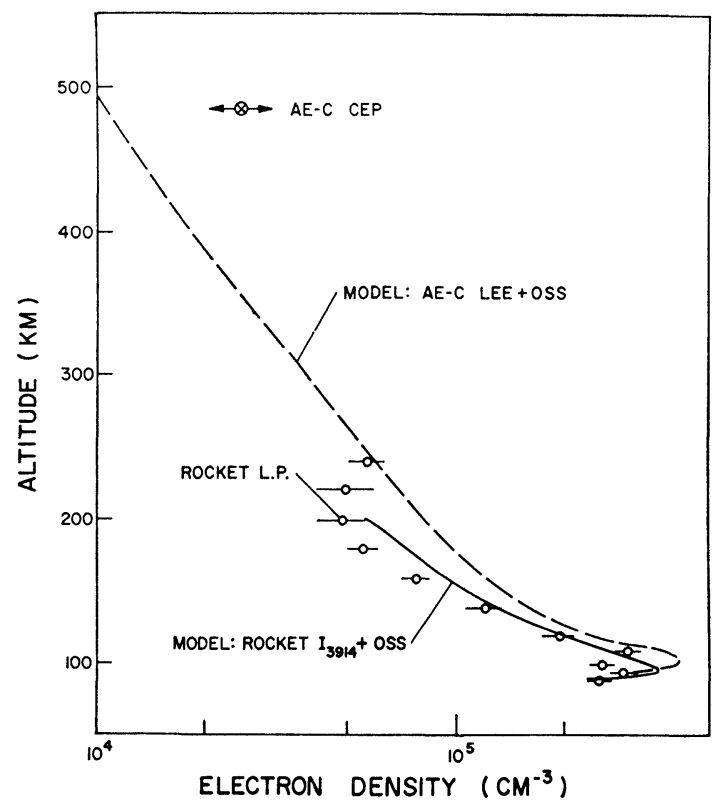

Fig. 11. Altitude profiles of electron density in the experiment of ReEs et al. (1977). Total ion measurements made by the satellite-borne cylindrical electrostatic probe (CEP) at $491 \mathrm{~km}$ and electron measurements by the Langmuir probe (LP) on the rocket between 90 and 240 $\mathrm{km}$ are shown together with model computations using the AE-C input data and rocket input data. 


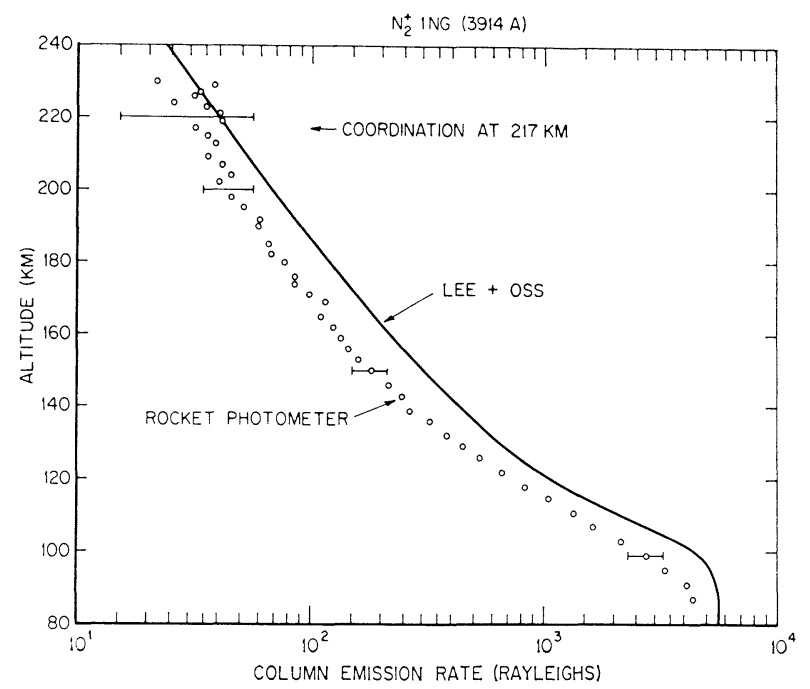

Fig. 12. Column emission rate of $\mathrm{N}_{2}^{+} 1 \mathrm{NG}(0,0)(3914 \AA)$ measured by the upward looking rocket-borne photometer and computed from the particle flux observed at the satellite altitude. LEE is the AE-C Low Energy Electron Experiment, while OSS is the AE-C Open Source Spectrometer which measures neutral gas densities. (From REES et al., 1977)

Figure 8 shows the total energy input from Joule heating and from precipitating electrons in the Evans et al. experiment. It is worthy of note that a smooth transition between regions dominated by these two energy sources occurs, with the strong field-aligned current coinciding with the poleward cutoff of substantial Joule heating, as expected if the Pederson current were diverted up the field line at that point.

We still, however, have no definite information on what relationship, if any, the large-scale inverted-'V's measured by satellites have with phenomena related to the data of Figs. 5 through 8. Polar-orbiting satellites capable of comprehensive measurements of particle and field parameters with spatial resolutions significantly below $1 \mathrm{~km}$ will first be required.

\section{Effects of Auroral Electrons in the Atmosphere}

The present state of knowledge on the atmospheric effects produced by auroral electron beams is well-summarized by the report of ReEs et al. (1977) on their recent coordinated satellite/rocket experiment. In this experiment the satellite Atmosphere Explorer C (AE-C) and a University of Michigan sounding rocket crossed the same L-shell with an east-west separation of $40 \mathrm{~km}$. Data on the input electron beam were obtained from AE-C, while the atmosphere was represented by a model atmosphere normalized to the simultaneous AE-C neutral gas data. Electron temperatures and densities were obtained both by satellite- and rocket-borne instruments. The output secondary electrons were measured at AE-C, while the output $3914 \AA$ nitrogen emis- 
sions were monitored by rocket-borne photometers. Figures 9 through 12 show the remarkable agreement between model calculations and actual data for this unique input-output experiment, with the $3914 \AA$ emission exhibiting the only significant disagreement.

\section{Summary and Conclusions}

Significant advances have occurred in our knowledge of the large-scale relationships between auroral morphology and magnetospheric particle populations and in the interaction of auroral electron beams with the atmosphere. By contrast, our ability to relate the large-scale phenomena measured from satellites to the smaller scale phenomena related to auroral arcs, and measured adequately only by rockets, is progressing only very slowly. It is crucial that coordinated sounding-rocket and satellite measurements be made with comparable spatial resolution if significant progress in this latter area is to be made.

This work was supported in part by National Aeronautics and Space Administration Contract NAS8-32584.

\section{REFERENCES}

ACKerson, K.L. and L.A. Frank, Correlated satellite measurements of low-energy electron precipitation and ground-based observations of a visible auroral arc, J. Geophys. Res., 77, 1128-1136, 1972.

Burch, J.L., S.A. Fields, W.B. Hanson, R.A. Heelis, R.A. Hoffman, and R.W. Janetzke, Characteristics of auroral electron acceleration regions observed by Atmosphere Explorer C, J. Geophys. Res., 81, 2223-2230, 1976.

Evans, D.S., N.C. Maynard, J. Troim, T. Jacobsen, and A. Egeland, Auroral vector electric field and particle comparisons, 2, Electrodynamics of an arc, J. Geophys. Res., 82, 2235-2249, 1977.

Heelis, R.A., W.B. Hanson, and J.L. Burch, Ion convection velocity reversals in the dayside cleft, J. Geophys. Res., 81, 3803-3809, 1976.

Hoffman, R.A. and J.L. BuRCH, Electron precipitation patterns and substorm morphology, J. Geophys. Res., 78, 2867-2884, 1973.

Lin, C.S. and R.A. Hoffman, Rapid fluctuations of inverted V electron fluxes, EOS, Trans. AGU, 58, 1210, 1977.

Lui, A.T.Y., D. Venkatesan, C.D. Anger, S.-I. Akasofu, W.J. Heikkila, J.D. Winningham, and J.R. Burrows, Simultaneous observations of particle precipitations and auroral emissions by the ISIS 2 satellite in the 19-24 MLT sector, J. Geophys. Res., 82, 2210-2226, 1977.

Maehlum, B.N. and H. Mostue, High temporal and spatial resolution observations of low energy electrons by a mother-daughter rocket in the vicinity of two quiescent auroral arcs, Planet. Space Sci., 21, 1957-1967, 1973.

McDiarmid, I.B., J.R. Burrows, and E.E. Budzinski, Average characteristics of magnetospheric electrons (150 eV to $200 \mathrm{keV})$ at 1,400 km, J. Geophys. Res., 80, 73-79, 1975.

Rees, M.H., A.I. Stewart, W.E. Sharp, P.B. Hays, R.A. Hoffman, L.H. Brace, J.P. Doering, and W.K. Peterson, Coordinated rocket and satellite measurements of an auroral event, 1, Satellite observations and analysis, J. Geophys. Res., 82, 2250-2258, 1977.

Reiff, P.H., J.L. Burch, and R.A. Heelis, Flow-aligned dayside auroral arcs, Geophys. Res. Lett., 1978 (in press). 
SNyder, A.L., Jr. and S.-I. Akasofu, Auroral oval photographs from the DMSP 8531 and 10533 satellites, J. Geophys. Res., 81, 1799-1804, 1976.

Winningham, J.D., S.-I. Akasofu, F. Yasuhara, and W.J. Heikkila, Simultaneous observations of auroras from the South Pole station and of precipitating electrons by ISIS 1, J. Geophys. Res., 78, 6579-6594, 1973.

Winningham, J.D., F. Yasuhara, S.-I. Akasofu, and W.J. Heikkila, The latitudinal morphology of $10-\mathrm{eV}$ to $10-\mathrm{keV}$ electron fluxes during magnetically quiet and disturbed times in the 2100-0300 MLT sector, J. Geophys. Res., 80, 3148-3171, 1975.

Winningham, J.D., T.W. Speiser, E.W. Hones, Jr., R.A. Jeffries, W.H. RoAch, D.S. Evans, and H.C. Stendaek-Nielsen, Rocket-borne measurements of the dayside cleft plasma: The Tordo experiments, J. Geophys. Res., 82, 1876-1888, 1977. 